\title{
O CPC DA UNE E O DEBATE SOBRE EDUCAÇÃO E CULTURA POPULAR NO BRASIL
}

\author{
EL CPC DE LA UNE Y EL DEBATE SOBRE EDUCACIÓN Y CULTURA \\ POPULAR EN BRASIL
}

\begin{abstract}
THE CPC UNE AND THE DEBATE ON EDUCATION AND POPULAR CULTURE IN BRAZIL
\end{abstract}

DOI: $10.22481 /$ rbba.v10i01.8793

\begin{abstract}
Marta Loula Dourado Viana Universidade Estadual do Sudoeste da Bahia, Brasil

ID Lattes: 8396550497066015

ORCID: https://orcid.org/0000-0002-3700-2822

Endereço eletrônico: mldviana@yahoo.com.br
\end{abstract}

\section{RESUMO}

Este artigo teve por objetivo apresentar uma discussão acerca das concepções de educação e cultura popular no Brasil, enraizadas pelo Centro Popular de Cultura (CPC) entre os anos 1961-1964. Foram identificados, pelo menos, três concepções como resultado das interlocuções entre diferentes grupos e classes sociais que tinham por finalidade o desenvolvimento nacional: a concepção nacional popular, a concepção de arte revolucionária e a concepção de educação e cultura de forma desinteressada. Estas concepções coexistiram, ora convergentes ora conflituosas, mas propuseram, enquanto ponto em comum, uma educação e cultura de modo a contribuir com a transformação social. A metodologia se baseou na historiográfica e bibliográfica. Para esta discussão foi basilar o acesso aos textos do Jornal Novos Rumos e da Revista Estudos Sociais, publicados na primeira metade dos anos 1960, como também às produções de autores contemporâneos que pesquisaram o CPC, a educação e cultura popular. A escolha dos referenciais se deu de acordo 


\title{
O CPC DA UNE E O DEBATE SOBRE EDUCAÇÃO E CULTURA POPULAR NO BRASIL
}

com o debate aqui proposto no contexto histórico em questão.

Palavras-chave: Educação; Cultura; Transformação social.

\section{RESUMEN}

Este artículo tenido como objetivo presentar una discusión sobre las concepciones de educación y cultura popular en Brasil, arraigadas en el Centro Popular de Cultura (CPC de la UNE) entre los años 1961-1964. Se identificaron al menos tres concepciones producto de las interlocuciones entre diferentes grupos y clases sociales que apuntaban al desarrollo nacional: la concepción nacional-popular, la concepción del arte revolucionario y la concepción desinteresada de la educación y la cultura. Estas concepciones convivieron, a veces convergentes y a veces conflictivas, pero proponían, como punto común, una educación y una cultura para contribuir a la transformación social. La metodología se basó en historiografía y bibliografía. Para esta discusión fue imprescindible tener acceso a los textos del Jornal Novos Rumos y la Revista Estudos Sociais, publicados en la primera mitad de la década de 1960, así como a las producciones de autores contemporáneos que investigaron el PCCh, la educación y la divulgación. cultura. La elección de las referencias se hizo de acuerdo con el debate aquí propuesto en el contexto histórico en cuestión.

Palabras clave: Educación; Cultura; Transformación social.

\begin{abstract}
This article aims to present a discussion about the conceptions of education and popular culture in Brazil, rooted by the Centro Popular de Cultura (CPC of UNE) between the years 1961-1964. At least three conceptions were identified as a result of the interlocutions between different groups and social classes that aimed at national development: the national-popular conception, the revolutionary art conception and the disinterested conception of education and culture. These conceptions coexisted, sometimes converging and sometimes conflicting, but they proposed, as a common point, an education and culture in order to contribute to social transformation. The methodology was based on historiography and bibliography. For this discussion, it was
\end{abstract}




\section{O CPC DA UNE E O DEBATE SOBRE EDUCAÇÃO E CULTURA POPULAR NO BRASIL}

essential to have access to the texts of the Jornal Novos Rumos and the Revista Estudos Sociais, published in the first half of the 1960s, as well as to the productions of contemporary authors who researched the CPC, education and popular culture. The choice of references was made according to the debate proposed here in the historical context in question.

Keywords: Education; Culture; Social transformation.

\section{INTRODUÇÃO}

Este artigo compõe uma parte das reflexões que fizemos durante o doutorado, e teve por objetivo apresentar uma discussão acerca das concepções de educação e cultura popular no Brasil, enraizadas pelo Centro Popular de Cultura (CPC) - uma organização associada à União Nacional dos Estudantes (UNE), criada em dezembro de 1961 e extinta pelo Golpe em 1964.

Em 1961, com menos de um ano de mandato, o presidente Jânio renunciava, pois eleito por forças contraditórias, não podia atender respetivamente as forças reacionárias e as camadas populares. Com sua renúncia, grupos reacionários, que defendiam a necessidade de o país se alinhar com o imperialismo estadunidense tentaram, sem êxito, impedir que o vice João Goulart, herdeiro da política populista de Vargas, tomasse posse. Para atenuar os poderes do vice, modificaram a Constituição substituindo o regime presidencialista pelo parlamentarista.

Os movimentos pelas reformas de base exerceram forte pressão social e política, e as correlações de forças políticas no Congresso culminou na revogação do regime parlamentarista, com isso João Goulart passou a governar no regime presidencialista a partir de 1963. O presidente Goulart e os grupos de esquerda organizaram uma ofensiva para garantir o apoio às reformas de base, por meio de uma série de grandes comícios a partir do dia 13 março de 1964 nas principais cidades do país, a fim de mobilizar a maioria da população brasileira em favor das reformas. As reações da burguesia nacional e de setores da sociedade civil foram imediatas, com articulação das Marchas da Família com Deus pela Liberdade. E o golpe foi efetivado em $1^{\circ}$ de abril de 1964.

Foi nesse contexto histórico que o CPC da UNE atuou na produção de uma cultura popular com fins educativo para o desenvolvimento da consciência social e de classe, e também atuou nas campanhas de alfabetização, com o objetivo de lutar pela transformação da realidade brasileira. O CPC se espalhou por todo o país e durante a sua existência dialogou com diferentes grupos políticos e sociais à época, dentre eles, podemos destacar o Instituto Superior de Estudos 


\section{O CPC DA UNE E O DEBATE SOBRE EDUCAÇÃO E CULTURA POPULAR NO BRASIL}

Brasileiro (ISEB), por exercer forte influência com a concepção nacional-popular, porém não sem concorrer com o entendimento do engajamento político marxista e do elemento de classe social na educação e cultura popular. O CPC também dialogou com outras organizações e experiências educacionais e culturais desenvolvidas neste período histórico de efervescência política.

Diante dessa interlocução, identificamos pelo menos, três concepções: a nacional popular, a arte revolucionária e a educação e cultura desinteressada. Estas concepções eram ora convergentes ora conflituosas, mas propuseram, enquanto ponto em comum, uma educação e cultura de modo a contribuir com a transformação social. A sistematização destas concepções foi possível por meio do acesso aos textos do Jornal Novos Rumos e da Revista Estudos Sociais, encontrados no Arquivo Marxista da Internet (MIA) e no Arquivo do Centro de Documentação e Memória (CEDEM- UNESP), publicados no início dos anos 1960, bem como da seleção de algumas produções de autores contemporâneos que estudaram o CPC. A escolha se deu de acordo com o debate aqui proposto no contexto histórico em questão.

\section{O CONCEITO DE POPULAR E O DESENVOLVIMENTISMO BRASILEIRO}

O Instituto Superior de Estudos Brasileiro (ISEB), criado em 1955 pelo Ministério da Educação e Cultura durante o governo de Juscelino Kubitschek, era composto por intelectuais de diferentes filiações teóricas e políticas com o objetivo de compreender a realidade brasileira e organizar estratégias para o desenvolvimento do capitalismo no país.

Se nas duas primeiras fases do ISEB a questão central foi a criação de medidas que viabilizassem o desenvolvimento nacional, na terceira e última fase entre os anos 1959-1964, com a constatação de um desenvolvimento industrial acompanhado da internacionalização do capitalismo no país e na não apropriação pelas massas populares e operária dos benefícios econômicos, houve um redirecionamento do entendimento sobre o desenvolvimento nacional, de acordo com o pensamento de três principais intelectuais próximos ao Partido Comunista no Brasil (PCB): Nélson Werneck Sodré, Álvaro Vieira Pinto e Roland Corbisier. Nesta última fase, foi garantida a concepção popular ao projeto nacional desenvolvimentista, fundamentada nas reivindicações pelas reformas de base durante o governo de João Goulart.

De acordo com Viana (2020), a concepção nacional popular sempre esteve presente nos debates internos do Partido Comunista no Brasil, mas ganhou enorme significado e 


\section{O CPC DA UNE E O DEBATE SOBRE EDUCAÇÃO E CULTURA POPULAR NO BRASIL}

desenvolvimento teórico nessa última fase do ISEB. No Partido, desde os meados dos anos 1930, para diferenciar sua concepção nacionalista, de unidade nacional independente de classe social, do nacionalismo burguês, foi acrescentado o adjetivo popular (nacional popular), que se tornou quase sinônimo de revolucionário.

Deste modo, para Olga (2011), o pecebista e isebiano Nélson Sodré desde sempre

[...] opunha-se à proposta de desenvolvimento do governo do Presidente Kubitschek, considerando que seu Programa de Metas mostrava que ele apenas pretendia acelerar o ritmo de crescimento econômico, sem tocar na estrutura, de sorte a alcançar determinados níveis meramente quantitativos, particularmente pelo ingresso maciço de capitais estrangeiros (SODRÉ, 2011, p. 17)

Para a autora, parece incorreto classificar o pensamento de Nélson Sodré afinado à linha nacional desenvolvimentista de Kubitschek, pois, a luta pelo desenvolvimento tinha como base a sua luta pela cultura com um nacionalismo de base popular, que pretendia atrair a burguesia brasileira e a ela se associar.

Nos primeiros anos do ISEB essas diferenças teóricas e políticas no campo da ideologia nacional desenvolvimentista coexistiram e somente entrou em colisão após o governo de Kubitschek, quando constataram o desenvolvimento econômico no país com a consolidação do capitalismo industrial e estrangeiro sem que resolvessem os problemas e as desigualdades sociais, os quais foram crescentes mediante a exploração do trabalho e do capital estrangeiro. Com isso, as diferenças se acentuaram no ISEB, e sob a direção de Álvaro Vieira Pinto, Roland Corbisier e Nélson Werneck Sodré iniciava uma nova fase, com uma posição "mais agressiva na crítica dos lucros das empresas estrangeiras, da remessa de lucros, da distribuição de renda e da transformação da estrutura agrária" (SODRÉ, 2011, p. 19).

O ISEB produziu debates, críticas e teorias acerca da realidade brasileira, e também formou a intelectualidade no país. Na última fase, houve uma aproximação mais concreta com a União Nacional de Estudantes (UNE), ambos sob a influência do PCB, que, mais tarde, culminou na criação do Centro Popular de Cultura (CPC). Não é demais ressaltar a troca de influências neste momento: o ISEB sob a influência do PCB que, naquele período de crescimento das lutas sociais, pautou-se por alianças com outros setores, tais como o trabalhismo - especialmente a esquerda nacionalista do PTB - e com a nova força católica de esquerda, a Ação Populari (AP) - constituída a partir dos movimentos pastorais progressistas. "Na UNE do PCB, em termos de direção política, prevaleciam as forças da AP; e no CPC, criado pela entidade estudantil, prevalecia uma maior influência do PCB” (LOVATTO, 2010, p. 101). 


\section{O CPC DA UNE E O DEBATE SOBRE EDUCAÇÃO E CULTURA POPULAR NO BRASIL}

Entendemos que foi da interlocução entre os vários grupos e setores com o PCB e seus intelectuais que surgiu a tônica de defesa de uma cultura popular, democrática e nacional. No entanto, o debate interno no Partido gerou uma pluralidade de concepções sobre o papel da cultura e da educação popular ora para o desenvolvimentismo, ora para a revolução, no limite, socialista. Da confluência do debate e da coexistência das divergências, acreditamos ser o Centro Popular de Cultura a organização mais avançada e complexa à época que melhor traduziu este contexto histórico. Entre os intelectuais pecebista podemos destacar Nelson Sodré e Caio Prado, os quais manifestaram discordâncias um ao outro.

Nélson Sodré (1967), defendia a construção de uma cultura nacional-popular como forma de superar o colonialismo cultural. Para ele, o colonialismo cultural impunha um conceito de cultura muito impreciso. Tratava-se ideologicamente do transplante cultural da Europa ocidental ou dos Estados Unidos para o Brasil colonizado e dependente economicamente. De tal modo que os restos de colonialismo permaneciam na estrutura social brasileira por interesse do capitalismo.

Nesse sentido que se dedicou a definir a categoria povo, considerando as antagônicas classes sociais e os interesses nacionais. $\mathrm{O}$ autor, ao analisar a dinâmica da categoria povo de acordo com o tempo histórico e o espaço social, encontrou um traço geral que permanece na definição de povo, a saber: um conjunto das classes, camadas e grupos sociais que possuem um objetivo em comum que é o interesse pelo desenvolvimento progressista e revolucionário. $\mathrm{O}$ intelectual admite a composição de diferentes classes, camadas e grupos sociais enquanto unidade, mesmo sabendo que seria uma ilusão por conta das contradições, mas que estas contradições não poderiam isolar um do outro, pois, para ele, o critério justo sobre o conceito de povo não poderia se restringir ao econômico.

Na relação entre povo e nação, entendia que povo e nação não são a mesma coisa, a política das classes dominantes não é nacional e as decisões em nome da nação não pertencem ao povo, portanto, “em política, como em cultura, só é nacional o que é popular" (SODRÉ, 1967, p. 193). Sob esta perspectiva, o povo divide-se em vanguarda e massa.

Massa é a parte do povo que tem pouca ou nenhuma consciência de seus próprios interesses, que não se organizou ainda para defendê-los, que não foi mobilizada ainda para tal fim. Faz parte das tarefas da vanguarda do povo, consequentemente, educar e dirigir as massas do povo. [...] Embora disponham de poderosos recursos e do domínio quase total do aparelho de difusão do pensamento e influam, por isso, ainda bastante sobre as massas, estas leem no livro da vida, que é muito, muito mais rico em ensinamentos do 


\section{O CPC DA UNE E O DEBATE SOBRE EDUCAÇÃO E CULTURA POPULAR NO BRASIL}

que os livros impressos, ou palavra falada, e a realidade as ensina, concretamente, todos os dias (SODRÉ, 1967, p. 209).

Ao analisar o conceito de povo no Brasil em sua constituição desde o século XX, Sodré entendia que as massas populares nunca tiveram participação nos destinos do país, isso não significava que não existia povo, mas o povo era constituído pelas classes burguesas e intermediárias. $\mathrm{O}$ autor notava que a independência do Brasil e a República foram tarefas progressistas, e não revolucionária. Para ele, as tarefas revolucionárias surgiriam com o desenvolvimento das forças produtivas e da acumulação que tornava o país, cada vez mais, capitalista.

Assim sendo, para uma participação efetiva das massas populares e trabalhadoras nos destinos do país, a educação e cultura popular teriam que se concentrar nas massas como uma das tarefas do povo, entendendo que o desenvolvimento da consciência e da organização das massas somente seria possível sob a vigência do regime democrático. Mas com a ênfase na vida delas por apresentar ensinamentos muito mais rico do que as abstrações dos livros impressos, por entender que a realidade ensina no cotidiano da vida. Sob esta perspectiva, para uma educação popular seria necessário considerar a vida das massas populares e trabalhadoras, como forma de garantir a democracia com a inclusão de seus elementos no processo de formação do povo brasileiro e de construção da cultura nacional.

Caio Prado Jr. (2000) definiu "povo" de modo diferente de Sodré. Ao analisar a história do povo brasileiro num processo de longa duração defendeu a tese de que o Brasil, desde a expansão marítima portuguesa, já era capitalista, o que contesta a tese sobre "restos feudais". Mas que ainda conservavam nas relações sociais, em particular as de classes, um acentuado cunho colonial. O "sentido de colonização", assim denominado, permanece no conjunto de acontecimentos e fatos essenciais num largo período histórico, na formação do povo sobre o desenvolvimento mundial do capitalismo e uma forma peculiar da realidade brasileira. Dessa forma, o conceito de povo estaria vinculado à situação de dominação política, cultural e, fundamentalmente, econômica. Portanto, para ele, a democratização da sociedade brasileira só seria possível ao se elevar o nível material e das condições de vida da generalidade da população.

Prado Jr., ao contrário de Sodré, argumentava que a burguesia nacional sempre se mostrou ligada ao compromisso imperialista do capital internacional, ainda que as frações da classe dela não se beneficiassem, evidentemente nunca houve uma representação progressista. 


\section{O CPC DA UNE E O DEBATE SOBRE EDUCAÇÃO E CULTURA POPULAR NO BRASIL}

Assim, a diferença entre os intelectuais está no que se refere às forças sociais revolucionárias. Para Prado Jr., a revolução não é um acontecimento com ruptura imediata, mas uma sucessão de reformas que enraíza a democracia como forma de garantir a participação popular e a construção da nacionalidade, já que o capitalismo se encontrava desenvolvido nas condições particulares da história brasileira. Mas este processo não podia estar nas mãos da burguesia brasileira, e sim nas mãos das forças populares. Para ele, as forças populares correspondiam aos setores populares e das massas trabalhadoras, os quais lutando contra a exploração do trabalho, lutariam contra o imperialismo e, verdadeiramente, em favor da questão nacional. Sobre isso, avalia Minto (2011):

No contraste das distintas respostas dadas, de um lado, por Nélson Werneck Sodré e, de outro lado, por Caio Prado Jr., pode-se observar a complexidade da realidade brasileira nesse período. Sodré era entusiasta da existência de um setor da burguesia brasileira que possuía interesses nacionais, com o que se poderia imaginar uma revolução democrática e nacional (em aliança com setores da pequena burguesia), e que o seu não reconhecimento seria uma forma de esquerdismo frágil, desprovido de bases históricas. Já Caio Prado Jr. repudiava a existência "teórica" (ou fantasiosa) de uma "burguesia nacional" capaz de liderar processos de transformação social ampliados, tarefa a ser empunhada pelos setores populares e pelas massas trabalhadoras (MINTO, 2011, p. 87-88).

E como os setores populares e as massas de trabalhadores lutariam contra a exploração econômica e do trabalho, contra o imperialismo e tudo quanto for atrasado? Para Prado (2000) esclarecendo-os sobre as relações bem como as contradições do capital com o trabalho. Com este apontamento do autor, entendemos que o popular na concepção de Sodré poderia se tornar populismo reacionário ou pseudopopular, ou seja, uma armadilha para conciliação de classes sociais antagônicas e substituição da apreensão crítica do mundo capitalista burguês por uma construção positiva e conciliatória entre as classes, camadas ou grupos sociais. Uma unidade nacional popular, de modo confinante à vida do povo, das massas populares e trabalhadoras, estas que se encontravam impregnada pelo "sentido de colonização".

A despeito desse debate, a perspectiva de defesa da construção da cultura nacional popular influenciou fortemente o Centro Popular de Cultura, mas não sem concorrer com o entendimento do engajamento político marxista na cultura popular e do elemento de classe.

Como afirma Garcia (2004):

Em geral, tanto o debate quanto a produção artístico-cultural vinculada às diretrizes estéticas e ideológicas do CPC da UNE foram indistintamente caracterizados como dogmáticos e panfletários, ora reflexo do "manifesto do CPC", ora produto da articulação entre populismo e nacionalismo. No entanto, 


\section{O CPC DA UNE E O DEBATE SOBRE EDUCAÇÃO E CULTURA POPULAR NO BRASIL}

alguns pesquisadores têm apresentado novas abordagens sobre o tema, na medida em que não priorizam aquele "manifesto do CPC" como tradução direta da arte engajada (GARCIA, 2004, p. 128).

Embora fosse comum a concepção de cultura e educação popular enquanto instrumentos didáticos, sociais e políticos, o CPC não era um grupo homogêneo, uma vez que foi fundado em 1961, no auge do intenso debate interno no PCB e na véspera da expulsão de cem membros por discordâncias políticas profundas acerca da nova linha em construção no Partido. A nosso ver, as divergências existentes dentro do Centro Popular de Cultura foram o reflexo das divergências internas no Partido, principalmente porque a maioria dos intelectuais e artistas do CPC eram do PCB. Dessa forma, a partir da afirmativa da autora, identificamos pelo menos três segmentos no CPC, que ora afluíam e ora se enfrentavam com profundos embates políticos e culturais.

Um segmento do CPC tinha relação com o Movimento de Cultura Popular (MCP) de Recife-PE e a Campanha de alfabetização "Pé no chão" em Natal - RN. Estes Movimentos, com o lema de construir uma cultura popular com o povo, tinha como um dos principais dirigentes o professor Paulo Freire ${ }^{\mathrm{ii}}$, e era composto por elementos das mais diversas filiações partidárias e filosóficas. Sobre esta aproximação dizia o Paulo Freire: "Sou católico, ortodoxo. Mas aqui trabalhamos com comunistas, também ortodoxos. Damo-nos as mãos, distanciados apenas naquilo que nos separa, que não é muito" (BORGES, 1962, p. 5). Este segmento se fundamentava na concepção nacional popular, nas alianças entre classes, camadas ou grupos sociais, até mesmo opostos, enquanto uma unidade em defesa dos interesses supostamente nacionais e de desenvolvimento nacional.

Outro segmento se mostrava mais radical e intransigente na luta contra o imperialismo, acreditando que a política de alianças e o nacional desenvolvimentismo era um desvio para a direita no sentido de camuflar os verdadeiros interesses particulares da burguesia nacional. Este segmento se expressava no Manifesto do CPC, em sua primeira fase presidido por Carlos Estevam Martins, no qual "apesar da intenção de formular uma concepção de 'arte popular revolucionária' com base no 'nacional-popular', é possível perceber claros vestígios de uma política cultural próxima ao realismo socialista" (GARCIA, 2004, p. 138). Acreditamos que com a expulsão desse segmento mais sectário do partido e a iniciada renovação do PCB em 1962, a influência do Partido no CPC resultou na hegemonia da concepção nacional-popular com certa herança do realismo socialistaiii.

Um terceiro segmento contestava a questão do realismo imposto na produção artística, de modo confinante a vida e ao trabalho das camadas populares bem como a questão estética 


\section{O CPC DA UNE E O DEBATE SOBRE EDUCAÇÃO E CULTURA POPULAR NO BRASIL}

da relação forma e conteúdo, que impediam a dinâmica e a criatividade. Para este segmento, em especial, representado pelo pecebista e intelectual Leandro Konder, tanto o conhecimento quanto a arte necessitavam do realismo, e vice-versa, não sendo, portanto, neutros. Mas o realismo não poderia ser uma camisa de força para que a educação e cultura tivessem uma função transformadora da sociedade e imposição do rebaixamento da forma em atendimento a um público ou grupo social.

A nosso ver, o CPC apresentou a coexistência ora pacífica e combinada ora em disputa destas três linhas políticas entre intelectuais e artistas filiados ou ligados ao debate interno do PCB. De um lado, o organismo de uma cultura popular com o povo, onde o povo independente de classe se organizaria para a educação popular e a produção cultural enquanto representação social, como forma de aprendizagem e de valorização do homem das massas populares nesse processo de (re)construção da nacionalidade brasileira. Apuseram, doutro lado, a necessidade de uma cultura popular revolucionária, na qual os elementos de classe social e de desalienação da mesma fossem privilegiados, tornando a educação e cultura popular tuteladas pelos intelectuais e artistas militantes, uma vez que o povo, enquanto uma representação das classes (operário, camponês e massas pobres), não estariam em condições de produzir sua própria cultura, em especial, para além da estética e da escolarização, de modo que produzisse uma consciência social e política de luta pelas questões nacionais, em favor da classe e contra o imperialismo. Por fim, a perspectiva de uma educação e cultura desinteressada, no sentido de elevar o nível de instrução e o desenvolvimento da consciência das camadas populares e classe trabalhadora, produzindo uma cultura nacional, democrática e popular sem o rebaixamento ou estática da produção artística, cultural e educacional.

Todavia, em que pese as dissensões, acreditamos que todos os segmentos apresentavam interesses na transformação social e na abordagem da realidade dos trabalhadores e massas populares: no significado de escutá-los e aprender com os mesmos, já que a dura vida e as condições de trabalho seriam grandes lições de aprendizagens; na necessidade de ensiná-los, ofertando uma educação e cultura popular com fundamentos políticos e marxista capazes de desalienação; como também na possibilidade de uma educação e cultura desinteressada.

\section{O CPC E O DIÁLOGO COM PAULO FREIRE}

Enquanto ideia comum, o CPC foi formado por um grupo de estudantes, intelectuais e artistas preocupados em elaborar e levar ao povo uma cultura que servisse para expressá-lo na 


\section{O CPC DA UNE E O DEBATE SOBRE EDUCAÇÃO E CULTURA POPULAR NO BRASIL}

luta por sua realidade existencial. A abordagem da realidade das massas populares e classe trabalhadora na produção cultural e na educação popular era um aspecto comum, com um caráter pragmático, tanto pela abordagem da vida e do trabalho do povo como aprendizagem e não marginalização quanto na pedagogização ou didatismo.

Era objetivo do CPC dos estudantes da UNE desenvolver campanha de alfabetização com o objetivo de eliminar o analfabetismo, mas também de unir cada vez mais o estudante ao povo, procurando torná-lo conscientes de sua realidade. Com a campanha de alfabetização em curso, Montana (1962) afirmou que os estudantes muito tinham aprendido com o povo. "A campanha tem sido um verdadeiro diálogo entre os que ensinam e vão aprendendo e os aprendem e vão ensinando" (MONTANA, 1962, p. 05).

Identificamos que a busca do CPC pela consciência da realidade social e nacional estava em contraposição às abstrações e ao verbalismo da ciência e da escola tradicional que não se conectavam aos interesses da classe trabalhadora, massas populares ou do povo brasileiro. É nesse sentido que a campanha de alfabetização e a construção de uma cultura popular originalmente nacional foram alavancadas pelo CPC. A campanha de alfabetização de adultos teve início em 1962. E já na primeira etapa, o CPC trouxe uma avançada reflexão:

Primeiramente, caíram os alfabetizadores no puro teoricismo. Pretendiam,
antes de qualquer aula, elaborar cartilhas e discutir planos, esquecendo-se de
que só a prática poderia lhes ensinar o rumo a tomar. Ao descobrirem seu erro,
caíram no extremo exposto. Começaram a dar aula sem nenhum plano prévio.
Dentro desse esquema praticista as aulas dadas nas favelas falharam.
Chegaram eles, então, através da experiência à conclusão de que era
necessário unir os dois aspectos. Nem teoria sem prática, nem prática sem
teoria. [...] A campanha ganhava um salto qualitativo muito grande com o
curso de alfabetizadores, que lhes veio trazer uma nova dimensão,
aumentando o número de alfabetizadores e de escolas. Deste curso foi feita
uma grande propaganda pelo rádio e jornais, de forma que a aula inaugural
dada por Anísio Teixeira foi um grande sucesso: assistiram mais de 100
pessoas. (MONTANA, 1962, p. 5).

No entanto, acreditamos que na ausência de uma teoria pedagógica e a emergência diante da disposição em alfabetizar a população brasileira, assim como, o entendimento da necessidade de uma prática pedagógica do e para o povo ou com o povo, se tratando, portanto, de uma "inovação", as aulas caracterizaram-se experimentais. E estas experiências dialogavam horizontalmente com outras em desenvolvimento por outros movimentos independentes do CPC. Como exposto, ainda, na reportagem: 


\section{O CPC DA UNE E O DEBATE SOBRE EDUCAÇÃO E CULTURA POPULAR NO BRASIL}

As aulas que vêm sendo dadas até agora são aulas experimentais. Não existe ainda um método desenvolvido, nem livros fixos. Existem apenas as linhas gerais fornecidas pelas experiências pedagógicas do mundo atual. Estar, porém, na ordem do dia, uma comissão pedagógica para sistematizar a própria experiência da campanha. [...] o grande sonho da campanha é organizar uma Universidade do Popular, onde haverá estudantes e operários, ao mesmo tempo, como alunos e professores, a teoria e prática aliada - e as artes mergulhadas na inspiração popular e para elas voltadas (MONTANA, 1962, p. 05)

As experiências pedagógicas referidas circunscreviam nas experiências do Movimento de Cultura Popular de Recife - PE e na Campanha de alfabetização "Pé no chão" em Natal RN. Em algumas matérias do Jornal Novos Rumos, percebemos como foram expressivos os entusiasmos com estas experiências das campanhas de alfabetização que se espalhavam por alguns estados do país e as quais tinham um papel para o processo de desenvolvimento nacional. Pronunciava a comunista Zuleika Alambert:

Entre os grandes problemas brasileiros que estão para ser resolvidos um destaca-se por sua importância: o do analfabetismo. País em processo de desenvolvimento econômico, social e cultural, o Brasil não pode de modo algum continuar indiferente à situação de milhares de brasileiros de todas as idades, que espalhado pelos quatro cantos da Nação vivem completamente a margem desse processo histórico, em virtude da ignorância e atraso em que vivem mergulhados. (ALAMBERT, 1963, p. 5)

Além disso, era recorrente nas reportagens a identificação de alguns pontos próximos entre os movimentos, imprimindo a positividade de ambos, tanto para o processo de desenvolvimento nacional quanto para a construção de uma educação e cultura popular, com o objetivo de as massas populares terem nas mãos os meios para lutar contra a situação de pobreza e exploração. Isso fica evidente nas seguintes passagens da reportagem:

O MCP, nos informou Liana Auraliano, jovem e entusiasta participante do movimento: "procura integrar o homem em sua realidade dando ao mesmo tempo a ele os meios para lutar contra sua situação". A cultura popular, dissenos também, "deve aproveitar as formas populares, dando a elas um conteúdo revolucionário". (MONTANA, 1962, p. 5)

Assim como o CPC:

[...] vem se desenvolvendo justamente pela receptividade encontrada no coração do povo. Esta é a sua cultura. A CULTURA DO POVO, PARA O POVO E PELO POVO. O CPC é um grito de entusiasmo, é um brado contra a exploração do homem brasileiro. É um exemplo profundo, dado pelos nossos estudantes, que identificam seu pensamento e sua ação com as necessidades da classe oprimida, a fim de "restituir ao povo brasileiro a consciência de si mesmo, para que possa criar uma sociedade e uma cultura em que todos os 


\section{O CPC DA UNE E O DEBATE SOBRE EDUCAÇÃO E CULTURA POPULAR NO BRASIL}

aspectos da atividade humana se voltam para o homem." (MONTANA, 1962, p. 5, grifos da autora)

É importante registrar que na elaboração da cartilha do Movimento de Cultura Popular, Paulo Freire se afastou sob o seguinte argumento: "Eu me lembro que já naquela época eu defendia uma coisa que eu vivo dizendo ainda hoje, a existência de textos de suporte, mas textos de suporte que sejam tão desafiadores como os slides que eu propus. E não a cartilha enquanto domesticadora" (FREIRE apud BEISIEGEL, 1974, p. 208-209). Dessa forma, as campanhas de alfabetização de adultos do MCP se desenvolviam com e sem cartilha. Paulo Freire elaborou um método de alfabetização e publicou em 1963 com o título Alfabetização e conscientização. Neste texto, fica evidente a preocupação do educador em educar de forma crítica e não apenas alfabetizar com codificação das sílabas e palavras.

No nosso método, a codificação, a princípio, toma a forma de uma fotografia ou de um desenho que representa uma situação existencial real ou uma situação existencial construída pelos alunos. Quando se projeta esta representação, os alunos fazem uma operação que se encontra na base do ato de conhecimento; se distanciam do objeto cognoscível. Desta maneira os educadores fazem a experiência da distanciação, de forma que educadores e alunos possam refletir juntos, de modo crítico, sobre o objeto que os mediatiza. O fim da descodificação é chegar a um nível crítico de conhecimento, começando pela experiência que o aluno tem de sua situação em seu "contexto real". [...] a procura temática implica na procura do pensamento dos homens, pensamento que se encontra somente no meio dos homens que questionam reunidos esta realidade. Não posso pensar no lugar dos outros ou sem os outros, e os demais também não podem pensar em substituição aos homens. (FREIRE, 1979, p. 18-19)

Ainda consideramos importante registrar, a relação de Paulo Freire com o Movimento de Educação de Base (MEB) da Igreja Católica, que também desenvolveu campanhas de alfabetização. Segundo Fávero (2006), no MEB o Padre Vaz fazia críticas ao marxismo e se incumbia de desenvolver a formação ideológica da Juventude Universitária Católica (JUC) como contraponto a sua proximidade com o movimento estudantil (UNE) do PCB. Em 1960 houve uma crise na Igreja. A JUC começou a criticar às causas do subdesenvolvimento e, sobretudo, o crescente imperialismo estadunidense, o que gerou problemas. Na verdade, a Igreja não esperava, nem admitia que ela viesse a assumir uma posição política, muito menos de contestação. Em decorrência dessa crise que, em 1962, foi criada a Ação Popular pelo grupo da JUC, o qual mantiveram interlocução com o PCB. 


\section{O CPC DA UNE E O DEBATE SOBRE EDUCAÇÃO E CULTURA POPULAR NO BRASIL}

No MEB também circulava uma forte influência do escolanovismo com a defesa da não-diretividade no processo educativo de modo a se contrapor ao autoritarismo e verbalismo da escola tradicional. Paulo Freire se unificava a esta defesa, e também defendeu o nacional desenvolvimentismo, assim como o ISEB e alguns setores do PCB. Estes últimos, desde a segunda metade dos anos 1940, defenderam a construção de uma cultura popular com o povo, de modo dialógico e horizontal. Dessa forma, apreendemos que o educador Paulo Freire elaborou sua proposta de alfabetização com o objetivo de uma conscientização política a partir dessa interlocução entre o Partido e as organizações experimentais. $\mathrm{O}$ termo conscientização usado por Freire foi fundamentado, de um lado, nos estudos realizados pelos intelectuais do ISEB, principalmente Álvaro Vieira Pinto e Roland Corbisier, e de outro lado, na contribuição do MEB, da JUC e da Ação Popular.

Ao analisar o método de Paulo Freire, bem como algumas cartilhas utilizadas pelo CPC em comparação às cartilhas do MEB, Gonzalez (2011) afirma que há semelhança e que o "Método Paulo Freire seria, assim, o elemento comum entre as duas propostas e que mediaria a ligação desses com as ideias pedagógicas hegemônicas no momento histórico-político e teórico-filosófico." (GONZALEZ, 2011, p. 88).

Em síntese, segundo Saviani (2007), Freire procurava organizar uma espécie de escola nova popular. Nos anos 1960, o escolanovismo no Brasil pouco a pouco estava adentrando nos setores de esquerda, e também os próprios católicos já estavam se renovando. Da interação desses grupos ou setores sociais com o CPC, é possível afirmar o uso de métodos e princípios do escolanovismo na educação popular, já que "propunha não apenas um sistema de ensino que respondesse às necessidades sociais (então traduzidas como necessidade de força de trabalho qualificada para o desenvolvimento), mas também uma prática pedagógica ligada à vida" (PAIVA, 2000, p.117).

Daí o entendimento de que a educação não se resume a codificar as palavras, ler textos, contar, dominar a gramática etc., mas seria, essencialmente, uma leitura crítica do mundo. Para Freire (1979), o letramento perpassa pela leitura consciente e crítica do mundo. Mas, isso seria um feito do próprio povo, das massas populares, não dirigindo-as, uma vez que, para ele, o acesso aos instrumentos educativos mais realistas contribuiria para o desenvolvimento de uma consciência crítica e, consequentemente, a transformação social.

Segundo Paiva (2003), o método de Paulo Freire seria a expressão mais acabada do que se caracterizava por "realismo em educação". O educador se tornou a expressão mais elaborada 


\section{O CPC DA UNE E O DEBATE SOBRE EDUCAÇÃO E CULTURA POPULAR NO BRASIL}

do que, mais precisamente a partir de 1930, se tornou comum entre os intelectuais nacionalistas, liberais, democratas, marxistas, comunistas etc., a saber: crítica contundente à escola tradicional do ponto de vista escolanovista.

A nosso ver, por conta da visão dualizada entre o "velho" e o "novo" acreditavam que somente a partir dos anos trinta as relações capitalistas começaram a se desenvolver com a modernização como possibilidades progressistas. Antes disso, as relações foram consideradas "feudais", transplantada da Europa por meio do processo de aculturação e do ensino elitizado, escolástico, verbalista e dogmático, no qual o trabalho físico era determinado para os não afortunados. Como afirmava Sodré:

"Força de conservação", o "ensino de classe, dogmático e retórico", padronizava a cultura, formava reduzida e rala minoria de letrados, ilhada pelo total desinteresse dos demais, marginalizada pelo conteúdo de alienação implícito no que aprendia e cultivava, desprovido tudo de senso crítico e distante do espírito criador (SODRÉ, 1974, p. 19-20)

Entretanto, acreditamos que as formas de confrontar a escola tradicional religiosa ou não no Brasil foram também transplantadas dos países capitalistas desenvolvidos, que após as revoluções industrial e francesa, ergueram-se contra o poder político da Igreja. Todavia, a burguesia ao se consolidar no poder econômico, político e intelectual, a ela se associa como antídoto contra as lutas sociais e trabalhistas à época na Europa. As críticas que fazem à escola tradicional, a qual a burguesia se serviu, são aquelas que os liberais escolanovista fizeram no processo contrarrevolucionário dos países imperialistas. Deste modo, acreditamos que, a teoria da existência de restos "feudais" no país, que impôs a revolução burguesa enquanto necessária, inevitável e progressista, os conduziram à ideologia desenvolvimentista com ampla colaboração entre classes, a fim de concretizar o capitalismo, o qual julgava não existir no Brasil.

Entendemos que, naquele momento, o que se teve enquanto concepção de esquerda mais avançada foi a teoria e o método do educador Paulo Freire, numa espécie de fusão de alguns princípios e método da escola nova (não-diretividade, liberdade, pragmatismo, etc.) com os ideais de transformação da realidade por meio dos movimentos de lutas sociais e reformas, bem como de uma educação e cultura em que a realidade das massas populares fossem consideradas como aprendizagens e, por isso, não estariam marginalizadas, ou seja, uma construção nacional com a valorização dos elementos das massas populares e trabalhadoras numa relação horizontal e dialógica, sem imposições de elementos considerados mais elaborados e externos. Em tese, 


\section{O CPC DA UNE E O DEBATE SOBRE EDUCAÇÃO E CULTURA POPULAR NO BRASIL}

uma imposição cultural ou de classe seria tão colonialista quanto de quando o Brasil foi colonizado.

O fato é que voltar-se para a realidade não parecia ser o suficiente para uma prática pedagógica transformadora, para uma educação e cultura popular revolucionária, pois a realidade estava impregnada de elementos de alienação social e de um sentido de colonização, como bem colocou Caio Prado. As ideias dominantes seriam as ideias da classe dominante, ou seja, a vontade da burguesia como uma vontade geral. Além disso, os liberais também reivindicavam uma aproximação com a realidade brasileira, porém no sentido estritamente pragmático e utilitarista da formação escolar em conformidade às demandas de mão-de-obra para as indústrias, com o idealismo de que a educação permitiria uma ascensão econômica e, portanto, um desenvolvimento nacional. A partir dessa compreensão, setores do CPC propuseram a necessidade de uma educação e cultura revolucionária fundamentada na luta de classes e no marxismo.

\section{O CPC E A ARTE REVOLUCIONÁRIA}

Diante do debate sobre a construção de uma cultura e educação popular, alguns intelectuais marxistas manifestaram preocupações com a política da classe dominante que, numa "frente popular", penetraria hegemonicamente nesse processo de reconstrução nacional e popular. Havia a necessidade de esclarecer os conceitos de cultura de elite e cultura popular. Para estes, a cultura popular teria que estar ligada aos interesses da classe trabalhadora, em oposição à cultura dominante burguesa que a explora e aliena da condição social, econômica e política. Dessa forma,

O objetivo primordial dos cepecistas não era, a rigor, a cultura, e menos ainda a diversão e o lazer. Queriam mesmo era penetrar a couraça da ideologia dominante e conscientizar os trabalhadores, atraí-los para as águas da revolução brasileira. Para isso, escarafuncharam a realidade nacional e local em busca de matéria prima que pudesse alimentar suas obras e colheram resultado não destituído de sucesso. (VIEITEZ, 2019, p. 182).

Foi nesse sentido que no Manifesto do CPC, em defesa de uma arte revolucionária, Carlos Estevam Martins distinguia a arte do povo e a arte popular da arte popular revolucionária. Para ele, "fora da arte política não há arte [verdadeiramente] popular" (MARTINS, 1980, p. 90): 


\section{O CPC DA UNE E O DEBATE SOBRE EDUCAÇÃO E CULTURA POPULAR NO BRASIL}

[...] a arte do povo é predominantemente um produto das comunidades economicamente atrasadas e floresce de preferência no meio rural ou em áreas urbanas que ainda não atingiram as formas de vida que acompanham a industrialização. $O$ traço que melhor a define é que nela o artista não se distingue da massa consumidora. Artista e público vivem integrados no mesmo anonimato e o nível de elaboração artística é tão primário que o ato de criar não vai além de um simples ordenar os dados mais patentes da consciência popular atrasada. A arte popular, por sua vez, se distingue desta não só pelo seu público que é constituído pela população dos centros urbanos desenvolvidos, como também devido ao aparecimento de uma divisão de trabalho que faz da massa a receptora improdutiva de obras que foram criadas por um grupo profissionalizado de especialistas. Os artistas se constituem assim num estrato social diferenciado de seu público, o qual se apresenta no mercado como mero consumidor de bens cuja elaboração e divulgação escapam ao seu controle. (MARTINS, 1980, p. 90).

Dessa diferenciação, a arte popular revolucionária foi considerada a melhor expressão produzida por dirigentes intelectuais, que atribuíam um paternalismo político fundamentado no marxismo para a revolução brasileira. A arte popular revolucionária expressava uma forma estética de fácil compreensão, uma vez que o objetivo seria a conscientização do povo para as tarefas revolucionárias. Como afirmava Ferreira Gullar:

A cultura popular é, em suma, a tomada de consciência da realidade brasileira. Cultura popular é compreender que o problema do analfabetismo, como o da deficiência de vagas nas universidades, não está desligado da condição de miséria do camponês, nem da dominação imperialista sobre a economia do país. Cultura popular é compreender que as dificuldades por que passa a indústria do livro, como a estreiteza do campo aberto às atividades intelectuais, são frutos da deficiência do ensino e da cultura, mantidos como privilégios de uma reduzida faixa da população. [...] Cultura popular é, portanto, antes de mais nada, consciência revolucionária. (GULLAR,1965, p. 3-4)

A concepção era a de que os trabalhadores e as massas populares precisavam ser dirigidos com uma teoria revolucionária fundamentada na luta de classes e na luta contra o imperialismo. Pois, sem escolarização e domínio do marxismo seriam incapazes de produzir uma cultura revolucionária. Cabiam aos artistas militantes e intelectuais ouvi-los e conectar-se com a realidade social no sentido de elaborar uma cultura que os expressassem e que ao mesmo tempo os fizessem refletir sobre a sua condição de vida e trabalho de modo consciente e transformador. Era como uma forma de fazer as massas operárias, camponesas e populares enxergarem os problemas da realidade social com indignação de sua condição para o objetivo da revolução socialista no país. 


\section{O CPC DA UNE E O DEBATE SOBRE EDUCAÇÃO E CULTURA POPULAR NO BRASIL}

Esta concepção partiu da contraposição aos recursos culturais publicitários e midiáticos que a burguesia nacional, ligada ao capital internacional, utilizava para entreter as massas, desinformando e distanciando as massas populares e trabalhadoras dos debates nacionais sobre os destinos políticos, sociais e econômicos. Para esta burguesia as diferenças regionais, de povos indígenas (e aqui os negros foram excluídos) e de classes sociais eram encaradas como exóticas, produzindo preconceito, quando não idealisticamente romântico, na composição diversificada da cultura nacional. Então, caberia aos intelectuais utilizarem dos recursos culturais para uma funcionalidade contrária, para qual a arte teria o importante papel da conscientização.

Nesse sentido, é perceptível uma negação da concepção de cultura popular folclórica. Como afirma Garcia (2004):

As coordenadas do "manifesto do CPC" sobre a arte de modo geral ("do povo", "popular" e "popular revolucionária"), constituíram uma forma de negação explícita da interpretação promovida anteriormente pelos folcloristas. Ainda que algumas perspectivas desses pesquisadores fossem recuperadas posteriormente, é possível perceber em autores como Carlos Estevam Martins, Ferreira Gullar e Nélson Lins de Barros uma espécie de negação absoluta da concepção de folclore e cultura popular romanticamente idealizada pelos folcloristas, em que o significado do termo popular está diretamente associado às manifestações culturais das classes populares que preservariam uma cultura antropológica, conservada em museus e necessária para alimentar o saber nostálgico dos intelectuais tradicionais (GARCIA, 2004, p. 140).

E diante das influências externas na composição da cultura nacional, assim como a imposição do modo de vida e cultura estadunidense, sob a forma imperialista no país, não podia deixar de enfatizar a questão nacional na produção de uma cultura popular brasileira. Sobre isso, enfatizava Gullar (1965), que a relação entre os princípios e valores vindos de fora e o processo cultural brasileiro não seria apenas inevitável, mas necessária e benéfica por permitir atualizações na aquisição de novos conhecimentos e aproximar povos distantes. Todavia, sem se submeter às injunções do mercado e não sem enfrentar criticamente o que vem de fora. Para ele, era fundamental não se submeter as influências externas e combater ao provincialismo acrítico que trabalhava contra os interesses nacionais. 


\section{O CPC DA UNE E O DEBATE SOBRE EDUCAÇÃO E CULTURA POPULAR NO BRASIL}

\section{EDUCAÇÃO E CULTURA DESINTERESSADA}

Outro elemento de grande discussão, que pudemos identificar, foi a relação conteúdo e forma, ao privilegiar o conteúdo em detrimento da forma estética, figurando uma forma de fácil compreensão a fim de criar um público operário e massas populares. Pois,

[...] a situação da classe operária era muito distinta. O teatro, o balé, a boa música, o bom cinema, em suma, as atividades às quais tinham acesso alguns setores das classes médias não integravam as tradições do operariado. O CPC tinha consciência disso. Sua criação foi, em parte, aliás, decorrência do inconformismo de seus intelectuais de terem que trabalhar exclusivamente para os segmentos sociais mais cultivados. Imaginaram, então, que poderiam adaptar a forma e o conteúdo dessas manifestações culturais ao gosto e nível de compreensão das camadas trabalhadoras. Esse esforço, que foi um grande esforço didático e pedagógico, antes que artístico, garantiu em muitos casos sucesso ribombante imediato a várias de suas produções e perenidade artística nenhuma. Uma arte que tinha o brilho de bolhas de sabão? Para os cepecistas, e mais ainda para seus artistas, não era assunto de somenos. (VIEITEZ, 2019, p. 185)

A cultura e educação seriam formas de abordar a realidade sem a preocupação com as exigências qualitativas da forma, como também o seu equilíbrio com o conteúdo. Deste modo, parecia não haver uma transcendência. O conteúdo estava muito à frente da forma. As campanhas de alfabetização e a produção cultural estagnaram-se na criação de um cidadão, de um público, de uma plateia, caindo na mesma lógica das relações de produção capitalista da cultura de massa, que impossibilitava o espírito criador de novas formas, novos conteúdos e uma nova realidade.

[...] percebeu, ou não se levou na devida conta, que a cultura (as artes etc.) só podem ser expressão muito mediatizada e complexa de um certo ambiente social; que a luta por uma nova cultura nem pode menosprezar as formas de atuação que lhes são próprias (o problema da estética), nem pode ignorar que ela deverá ter um caldo de cultivo numa certa dinâmica das relações sociais fundamentais. (VIEITEZ, 2019, p. 187)

De modo geral, a questão estética não era uma preocupação do CPC, assim sendo sobrepunha o conteúdo da realidade ao sentido estético e este às formas de mais fácil acesso aos não escolarizados, com o objetivo pontual de refletir e responder aos problemas sociais vigentes, o que traduz a presença de um certo realismo socialista na concepção nacionalpopular, esta que buscava incessantemente a identidade nacional e o povo brasileiro.

Ainda que algumas concepções de educação e cultura popular do CPC expressassem um realismo que se contrapunha ao romantismo burguês, para Ridenti (2001), paradoxalmente, a irrupção da categoria "povo" no imaginário das esquerdas brasileiras, do combate da esquerda 


\section{O CPC DA UNE E O DEBATE SOBRE EDUCAÇÃO E CULTURA POPULAR NO BRASIL}

armada às manifestações político-culturais na música popular, no cinema, no teatro, nas artes plásticas e na literatura, pode ser compreendida como manifestação de "romantismo revolucionário ${ }^{\mathrm{iv}}$ ".

Para o autor, havia um paradoxo entre a linha do Partido e os artistas militantes; se entre os artistas militantes havia um voluntarismo político em busca de uma nação futura, no limite, socialista, na linha do Partido, ao contrário do romantismo revolucionário, havia uma

[...] luta contra o poder remanescente das oligarquias rurais e suas manifestações políticas e culturais; um otimismo modernizador com o salto na industrialização a partir do governo Kubitschek; também um impulso revolucionário, alimentado por movimentos sociais e portador de ambiguidades nas propostas de revolução brasileira, democrático-burguesa (de libertação nacional), ou socialista, com diversas gradações intermediárias. (RIDENTI, 2001, p. 14)

Nesse sentido que o debate interno no Partido se aprofundava. E como terceira via de debate acerca do papel dos intelectuais na sociedade, Konder (1962) afirmava que as atividades intelectuais não podiam ser reduzidas ao praticismo e voluntarismo, com uma missão histórica a cumprir. $\mathrm{O}$ autor destacava que a exigência de fidelidade com a realidade e com o marxismo na produção cultural, através da qual se definia quem é revolucionário ou reacionário, não significava que ao considerar a realidade e se fundamentar no marxismo, sua produção ficasse coerente, assim, isso não se tornava suficiente, uma vez que "a imagem fiel de uma sociedade não pode deixar de ser, também, a imagem das contradições em que se debate essa sociedade" (KONDER, 1962, p. 5). Para ele, o papel revolucionário dos intelectuais marxistas deveria ser sim intensificado pelas suas forças e multiplicar as formas de atuação na vida cultural do país, mas em diálogo e debate franco com os demais intelectuais, com a clareza de argumentações e sem a necessidade de imposições que podem direcionar a equívocos interpretativos da realidade e erros no uso do método nas produções intelectuais.

Konder (1963) ilustrava que o conhecimento não é neutro. Portanto, o realismo reivindicado pelo CPC tinha fundamento, mas este realismo não poderia prejudicar o caráter propriamente artístico de uma obra, ou contribuir para baixar-se o nível estético e muito menos apresentar a atitude de submissão do homem em relação à realidade, como uma camisa de força que obrigatoriamente se deve vestir.

Dessa forma, o intelectual marxista não negava o realismo, uma vez que preza pela verdade, e afirmava que revolucionários consequentes precisam do realismo na arte e da arte no realismo, pois, precisam de uma política cultural eficaz. Contudo, contestava o sectarismo 


\section{O CPC DA UNE E O DEBATE SOBRE EDUCAÇÃO E CULTURA POPULAR NO BRASIL}

imposto pelo realismo. Esta imposição se tornava um romantismo revolucionário, pois em lugar de proporcionar um conhecimento da realidade efetiva, do processo histórico concreto, almejava proporcionar um conhecimento em busca da sociedade futura e perfeita, precipitavase, procurando soluções com certo idealismo político voluntarista.

Para Konder (1963), as produções artísticas e intelectuais precisam ser valorizadas pelo que elas são e não pelo valor aos olhos de quem a cultiva. Não enquanto uma subordinação de serviços determinada pela adesão ao Partido e a vida das camadas populares e trabalhadoras. Em concordância com o autor, acreditamos que, sem dúvidas, a vida dá formas fecundas às produções artísticas e intelectuais, bem como educacionais, mas também pode contê-las nos limites dela, quando a ela se subordinarem.

\section{CONSIDERAÇÕES FINAIS}

Do exposto sobre estas três questões nos debates do CPC: a concepção nacional popular, a concepção de arte revolucionária, e a concepção de educação e cultura desinteressada, não é demais afirmar a existência de uma colaboração conflituosa de concepções e de práticas que marcaram os debates entre os intelectuais de esquerda.

O contexto histórico de surgimento e atuação do CPC, foi marcado pela renúncia de Jânio Quadros e a luta pela legalidade do governo de Goulart bem como a luta pelas reformas de base. Estavam envolvidos nesta trama diversos setores e movimentos da sociedade brasileira, com evidente uso das palavras "povo" e "massas" como slogan para articular forças numa mesma direção, supostamente em defesa da questão nacional. Era objetivo do CPC da UNE “criar uma ferramenta pedagógica, disposta a motivar, predispor e criar atitudes favoráveis à participação política das pessoas e pela finalidade desejada pelos integrantes de produzir a cultura com a participação popular” (MOTA, 2018, p .17).

A nosso ver, neste período, foi notável o desenvolvimento cultural do país e a relevância da existência do CPC enquanto síntese da interlocução entre os diferentes grupos sociais. Mas, como afirma Mota (2018), o culturalismo resolvia apenas em parte a questão nacional, resolve talvez no campo das ideias, subsistiam as desigualdades em termos econômicos, sociais, raciais, sexo etc. Além disso, entendemos que a arte popular brasileira nunca se tornou, ainda hoje, popular na sua produção, nem na distribuição e nem no consumo.

Os CPCs espalhados pelo país enfrentaram a falta de interesse da maioria das massas populares e trabalhadoras tanto pela arte quanto por assuntos políticos e socioeconômicos. 


\section{O CPC DA UNE E O DEBATE SOBRE EDUCAÇÃO E CULTURA POPULAR NO BRASIL}

Entendemos que embora tenha sido uma louvável tentativa de construir uma cultura popular de modo crítico e politizado, tanto na expressão do Manifesto quanto na concepção nacional popular, sem os riscos de confundir com a cultura de "massa" ou de nivelar à cultura erudita, a cultura popular brasileira, apesar de sua riqueza, não resolveu as dicotomias entre o popular e o erudito e entre o popular e a cultura de massa.

Entretanto, entendemos que apesar dessa afirmativa, das consideráveis pesquisas sobre o CPC da UNE e do reconhecimento de seu potencial e significado que demonstrou em termos não apenas de sua atuação, mas também do complexo e avançado debate que ocorreu, faz-se necessário mais estudos, principalmente porque o CPC se espalhou por todo país, e diante das divergências e do contexto de múltiplos movimentos de diferentes setores sociais, políticos e regiões brasileiras, não se pode denominá-lo como um movimento homogêneo. Principalmente, por conta do intenso debate entre intelectuais, artistas militantes e o PCB sobre como o nacional popular deveria ser representado na cultura brasileira.

\section{REFERÊNCIAS}

ALAMBERT, Zuleika. “De pé no chão também se aprende a ler”. Jornal Novos Rumos, n’. 245, 1963. Arquivo Marxista da Internet - MIA.

BEISIEGEL, Celso de Rui. Estado e educação popular: um estudo sobre a educação de adultos. São Paulo: Pioneira, 1974.

BRANDAO, Carlos Rodrigues. A questão política da Educação Popular. São Paulo: Brasiliense, 1981. v. 1.

BORGES, Carlos F. No Recife, cultura é movimento popular. Jornal Novos Rumos, $\mathrm{n}^{\circ} .156$, 1962. Arquivo Marxista da Internet - MIA.

FÁVERO, Osmar. Uma pedagogia da participação popular: análise da prática educativa do MEB -Movimento de Educação de Base (1961/1966). Campinas: Autores Associados, 2006.

FREIRE, Paulo. Conscientização: teoria e prática da libertação: uma introdução ao pensamento de Paulo Freire / Paulo Freire; [tradução de Kátia de Mello e silva; revisão técnica de Benedito Eliseu Leite Cintra]. - São Paulo: Cortez \& Moraes, 1979.

GARCIA, Miliandre. A questão da cultura popular: as políticas culturais do Centro Popular de Cultura (CPC)da União Nacional dos Estudantes (UNE). Revista Brasileira de História. São Paulo, v. 24, no 47, p.127-62 - 2004.

GONZALEZ, Jeferson Anibal. Cultura, educação popular e transformação social nas formulações do MEB e do CPC (1961-1964). 2011. Dissertação de Mestrado do Programa de Pós-graduação da Unicamp, Campinas. 


\section{O CPC DA UNE E O DEBATE SOBRE EDUCAÇÃO E CULTURA POPULAR NO BRASIL}

KONDER, Leandro. Sobre a questão dos intelectuais. Jornal Novos Rumos, nº 166, 1962. Arquivo Marxista da Internet - MIA.

. Alguns problemas do realismo socialista. Revista Estudos Sociais, $n^{\circ}$. 17,1963. São Paulo, Arquivo do Centro de Documentação e Memória (CEDEM- UNESP).

MINTO, Lalo W. A educação da "miséria": particularidade capitalista e educação superior no brasil. 2011.Tese apresentada na Faculdade de Educação da Universidade Estadual de Campinas; Campinas.

LOVATTO, Angelica. Os cadernos do povo brasileiro e o debate nacionalista nos anos 1960: um projeto de revolução brasileira. 2010. Tese de Doutorado do Programa de Pósgraduação da Universidade Católica de São Paulo.

LÖWY, M. e SAYRE, R. Revolta e melancolia - o romantismo na contramão da modernidade. Petrópolis-RJ, Vozes, 1995.

MARTINS, Carlos Estevam. Anteprojeto do Manifesto do Centro Popular de Cultura redigido em março de 1962. In: HOLLANDA, H. B. de. Impressões de viagem: CPC, vanguarda e desbunde: 1960/1970. São Paulo: Brasiliense, 1980.

MONTANA, Regina. Combatendo o analfabetismo e unindo o estudante ao povo. Jornal Novos Rumos, $n^{\circ}$. 176, 1962. Arquivo Marxista da Internet - MIA.

. CPC: cultura do povo, para o povo e pelo povo. Jornal Novos Rumos, $\mathrm{n}^{\circ} .174$, semana 15 a 22 de junho de 1962. Arquivo Marxista da Internet - MIA.

MOTA, Danilo Henrique Faria. O nacional-popular e a dramaturgia de Vianinha no centro popular de cultura (CPC) da união nacional dos estudantes (UNE). 2018Dissertação apresentada ao Programa de Pós-graduação em Artes Cênicas do Instituto de Artes da Universidade Federal de Uberlândia, Minas Gerais.

NAPOLITANO, Marcos. A relação entre arte e política: uma introdução teóricometodológica. Temáticas, Revista de Pós-graduação em Sociologia/Unicamp, Campinas, v. 37 38, p. 25-56, 2011.

PAIVA, Vanilda. Paulo Freire e o nacional-desenvolvimentismo. São Paulo: Graal, 2000.

História da Educação Popular no Brasil: educação popular e educação de adultos. 6 ed. São Paulo: Loyola, 2003.

PRADO JR. Caio. Formação do Brasil Contemporâneo. São Paulo: Brasiliense/Publifolha, 2000.

SAVIANI, Dermeval. História das ideias pedagógicas no Brasil. Campinas - SP: Autores Associados, 2007.

SODRÉ, Nelson Werneck. Introdução à Revolução Brasileira. $3^{\text {a }}$ edição. Rio de Janeiro: Civilização brasileira, 1967. 


\section{O CPC DA UNE E O DEBATE SOBRE EDUCAÇÃO E CULTURA POPULAR NO BRASIL}

SODRÉ, Olga. O ISEB, Nelson Werneck Sodré e a cultura brasileira: um testemunho histórico. Albuquerque: revista de História, Campo Grande, MS, v. 3 n. 6 p. 9-21, jul./dez. 2011.

VIANA, Marta Loula Dourado Viana. Educação, cultura e revolução: O PCB e os intelectuais marxistas no período nacional desenvolvimentista (1946-1964). 2020.Tese de Doutorado do Programa de Pós-graduação em Educação da Unicamp, Campinas.

VIEITZ, Candido Geraldez. Reforma nacional democrática e contrarreforma no ABC paulista1956-1964. $2^{a}$ edição. Marília: Lutas Anticapital, 2019.

\section{NOTAS}

\footnotetext{
i Ação Popular criado em 1962 por um grupo da Juventude Universitária Católica (JUC) que criticava às causas do subdesenvolvimento e, sobretudo, o crescente imperialismo estadunidense, o que gerou uma crise na Igreja.

ii Paulo Freire. Vanilda Paiva, em seu livro Paulo Freire e o nacionalismo desenvolvimentista, aponta que Freire concorda com as teses expostas pelos isebianos. O CPC utilizou a metodologia desenvolvida por Paulo Freire no que ficou conhecido genericamente como - Método Freire. Segundo Carlos Rodrigues Bandão (1981), o método foi — testado primeiramente em Recife-PE e depois em Angicos e Mossoró-RN pela equipe do Serviço de Extensão Universitária da Universidade Federal de Pernambuco liderada por Paulo Freire. O trabalho de alfabetização com o método se inicia com a pesquisa do universo vocabular do educando; esse momento visa - surpreender a maneira como uma realidade social existe na vida e no pensamento, no imaginário de seus participantes (BRANDÃO, 1981, p. 28).

iii $\mathrm{O}$ realismo socialista foi um termo recuperado por Andrei Jdanov no I Congresso dos Escritores Soviéticos em 1934, pelo Partido Comunista da URSS, no período Stalinista, com as definições de uma cultura e educação proletária, assim como uma função socioeducativa e política. Logo depois, houve debates sobre o realismo socialista na arte com liberdade de criação, não panfletário e não restrito à vida real. Para saber mais indicamos Marcos Napolitano (2011), texto em que discute a origem e a polissemia conceitual que se esconde dentro do termo "realismo".

iv Expressão cunhada por Michael Lowy \& Robert Sayre (1995), para os quais, o romantismo apresenta três tendências gerais: uma primeira tendência pretende recriar o paraíso no plano imaginário, como projeção utópica, geralmente encontrada nas produções artísticas; a segunda tendência buscaria o paraíso no presente real, em países exóticos, não contaminados pela realidade capitalista; por fim, a terceira tendência visualiza a criação do paraíso no futuro, sendo as lembranças do passado armas na luta para o futuro. Trata-se do romantismo revolucionário, visto não como o retorno ao passado, mas como uma visão social de mundo e voluntarismo político.
} 